\title{
PREPARO DA CRIANÇA E FAMÍLIA PARA \\ PROCEDIMENTOS CIRÚRGICOS: INTERVENÇÃO DE ENFERMAGEM*
}

\author{
Edelia del Pilar Neira Huerta**
}

\begin{abstract}
NEIRA HUERTA, E. del P. Preparo da criança e família para procedimentos cirúrgicos: intervenção de enfermagem. Rev. Esc. Enf. USP, v.30 , n.2 , p.340-53, ago. 1996.

A autora apresenta os fundamentos do preparo da criança e sua família para procedimentos cirúrgicos, relacionando também aspectos relevantes como: o quê considerar ao realizar um preparo adequado; recursos necessários para implementálo; quando, onde e como fazê-lo, bem como o quê esperar da criança que foi adequadamente preparada.
\end{abstract}

UNITERMOS: Preparo da criança para procedimentos cirúrgicos e hospitalares. Enfermagem Pediátrica.

\section{INTRODUÇÃO}

Na nossa vivência profissional temos acompanhado com satisfação a paulatina entrada e permanência dos pais de crianças hospitalizadas, bem como de brinquedos naquelas unidades pediátricas em que supervisionamos as atividades práticas desenvolvidas por alunos de graduação em enfermagem. Essa mudança tem representado para nós uma lenta, porém segura caminhada em direção a uma abordagem mais adequada, mais integral e mais holística da assistência à criança hospitalizada.

Infelizmente o preparo da criança para procedimentos não tem acompanhado esse processo de mudança, sendo ainda raramente implementado. À maioria das crianças hospitalizadas oculta-se-lhes informações em relação aos procedimentos a que serão submetidas e, não raro, outras são enganadas, tanto pelos pais como pela equipe hospitalar, quanto ao procedimento e a seu propósito. Nossa percepção dessas situações nos leva a acreditar que o temor de não saber como lidar com as eventuais reações da criança os faz preferir ocultar informações ou até mentir sobre o procedimento e sua finalidade ${ }^{20}$.

\footnotetext{
* Conferência proferida no III Congresso Paulista de Cirurgia Pediátrica e I Jornada de Enfermagem em Cirurgia Pediátrica, São Paulo, ouubro, 1993.

** Enfermeira. Mestre em Enfermagem Pediátrica pela Escola de Enfermagem da USP.
} 
Na literatura estrangeira sobre o assunto encontramos inúmeros estudos e trabalhos, alguns dos quais publicados já há três décadas ou mais ${ }^{15,24}$. Entretanto, é reduzido ainda o número de publicações a esse respeito em língua portuguesa, e, todas elas, ou são muito gerais ${ }^{10,13}$, ou correspondem a resultados de trabalhos restritos pelas características da população estudada na experiência particular $1,8,9,11,1217,18$.

Assim, com a finalidade de oferecer às enfermeiras de unidades pediatricas elementos que lhes facilitem a implementação adequada do preparo psicológico da criança e de sua família para procedimentos cirúrgicos, propus-me a realizar estudo bibliográfico sobre o tema com objetivo de responder as seguintes questões: por que preparar a criança para procedimentos cirúrgicos? Por que preparar sua família? O quê considerar para realizar o preparo? Quais os recursos necessários para implementá-lo? E, o quê esperar da criança que foi adequadamente preparada? As respostas encontradas para cada um desses questionamentos são apresentadas a seguir.

\section{PORQUE PREPARAR A CRIANÇA PARA PROCEDIMENTOS CIRÚRGICOS}

Há já algumas décadas, no mundo todo, as crianças íam ao Centro Cirúrgico sem saberem o que ía acontecer com elas; pensava-se então ser melhor não estimular de antemão o medo da criança e ser também melhor não discutir a experiência com elas apos a cirurgia, acreditando que elas a esqueceriam rapidamente ${ }^{16}$. Posteriormente, com os conhecimentos que as pesquisas foram trazendo, foi estabelecido como "direito da criança o de saber a verdade em relação à realidade da experiência que deveria enfrentar, uma cirurgia"16.

Para qualquer pessoa, de qualquer faixa etária, a intervenção cirúrgica representa uma circunstância crítica que gera uma crise vital: "episódio de alteração psicológica de caráter agudo e de duração limitada que se apresenta como um obstáculo que o indivíduo não pode evitar nem resolver com seus recursos habituais"16. A população infantil é a mais sensivel a esta crise. Isto porque, devido a seu desenvolvimento imaturo, a criança tem recursos limitados para enfrentar situações desconhecidas e/ou dolorosas; sua capacidade para raciocinar logicamente e considerar as razões reais para a experiência é limitada e porque, para superar o medo, a frustração e a dor, ela geralmente recorre à fantasia ${ }^{5,21}$.

A experiência de vida da criança também é limitada e, devido às características de seu pensamento (egocêntrico), ela pode interpretar de forma errada os procedimentos dolorosos e invasivos, podendo inclusive interpretá-los como castigo ou punição e, conseqüentemente, sentir-se culpada ${ }^{5,14,22,24}$. 
Torna-se então necessário proporcionar à criança recursos que the facilitem a percepção da realidade da experiência e de seu propósito, bem como dar-lhe o apoio que lhe permita expressar em segurança e de acordo com seu nível de desenvolvimento, as emoções decorrentes da mesma. Quando a criança compreende a verdadeira finalidade do procedimento, ela é capaz de tolerar melhor o desconforto e a dor ${ }^{5,10}$.

Quando não preparada, a criança poderá:

- desenvolver sintomas psico-emocionais pós-cirúrgicos associados à cirurgia/hospitalização, tais como: fobias, pesadelos, insônia, enurese noturna e diurna, distúrbios de linguagem, temor de pessoas vestidas de branco, incapacidade de interagir com outras crianças e de brincar, agressividade (com a intenção inconsciente de afastar qualquer outro perigo), etc ${ }^{16}$. Ansiedades que às vezes parecem terem sido bem dominadas na época da cirurgia podem ser reativadas em crises futuras na vida, como na crise normal da adolescência por exemplo. Há relação direta entre o mentir ou não informar à criança sobre a cirurgia e seu propósito real e a gravidade dos sintomas emocionais posteriores ${ }^{16}$.

- $\quad$ perceber a experiência como ataque hostil, como um abuso, uma violência, o que pode levá-la a perder a confiança nos adultos ao seu redor, particularmente naqueles mais significativos em sua vida, seus pais, confiança essa essencial ao seu desenvolvimento emocional sadio ${ }^{5,21}$.

Conseqüentemente, a criança deve ser adequadamente preparada para procedimentos cirúrgicos para deste modo:

- diminuir o impacto potencialmente traumático da crise que representa a cirurgia e, assim, diminuir o risco de sintomas/distúrbios emocionais a ela associados, e

- minimizar o medo e ajudar a criança a experimentar um senso de domínio da realidade de uma experiência potencialmente traumática.

\section{PORQUE PREPARAR A FAMÍLIA PARA PROCEDIMENTOS CIRÚRGICOS}

Uma vez que tudo que afeta a um membro do sistema familiar, afeta, de uma forma ou de outra, a todos e a cada um de seus membros, a família nãopode ficar de lado. Assim sendo, não é apenas a criança que está em crise, a família está em crise. O nosso cliente, como em qualquer área da Enfermagem, não é apenas o paciente, mas o binômio inseparável paciente/cliente - família ${ }^{3}$.

Isto é particularmente verdadeiro no caso da criança, uma pessoa em 
desenvolvimento que, de acordo com suas habilidades de desenvolvimento, depende em diferentes graus dos relacionamentos, da dinâmica familiar para desenvolver da maneira mais sadia possível o máximo do seu potencial.

A família representa a principal fonte de segurança e de apoio para a criança. A família adequadamente preparada estará em condições para desempenhar seu papel "protetor", provendo o apoio e a segurança de que a criança tanto precisa para enfrentar a experiência ${ }^{3}$. A família preparada estará também melhor habilitada para participar de maneira mais apropriada dos cuidados pós-operatórios, bem como de continuar a cuidar após a alta hospitalar ${ }^{22}$.

Toda crise representa potencial de crescimento. A crise de uma cirurgia numa criança representa a oportunidade para a família crescer, aprendendo formas mais adequadas de relacionamento, bem como de fortalecer seus recursos para enfrentar futuras crises ${ }^{3}$.

Apenas quando a família é preparada, a experiência de cirurgia de um filho pode se tornar uma experiência de crescimento familiar. Através do preparo adequado, os pais podem aprender técnicas mais apropriadas de comunicação, não apenas com a criança em questão, mas também com outros filhos, e, até mesmo, entre eles, os pais. A família preparada para a experiência terá aprendido formais mais eficientes para lidar com crises similares e terá mais recursos para enfrentá-las.

\section{O QUE CONSIDERAR PARA REALIZAR O PREPARO}

A forma particular em que a criança percebe e interpreta a situação real é a que determina tanto o conteúdo como o método mais apropriado de preparo ${ }^{2,7}$, 10, 14, 15, 16, 22. Assim sendo, torna-se essencial:

- avaliar o nível de desenvolvimento da criança, particularmente seu nível de compreensão (nível cognitivo-adaptativo), lembrando que até os 3 anos a compreensão da criança limita-se ao concreto e palpável e a criança toma conhecimento de si e de seu mundo e dos objetos nele contidos através de seus sentidos. Até os 5 anos a criança é incapaz de dar uma definição, um conceito, ela apenas repete a palavra que lhe for dita. Entre 6 e 8 anos ela já define e interpreta as coisas em torno de seu uso. Entre 9 e 11 anos a criança já consegue dar sinônimos e classificar, isto é, é capaz de conceituar os objetos. Ao redor dos 12 anos a criança atinge a lógica do pensamento adulto, sendo, portanto, capaz de conceituar os objetos, de realizar abstrações e de fazer deduções a partir das relações entre esses conceitos abstratos ${ }^{6,10,15,16,22,23,24 .}$

Uma vez que a experiência de ser submetida a um procedimento cirúrgico pode interferir nas tarefas psico-sociais que nesse momento a criança se empenha em desenvolver, como também afetar áreas de seu corpo relacionadas 
à obtenção de prazer, é também muito importante, dentro do possível, determinar em que nível do desenvolvimento psico-social e psico-sexual a criança se encontra ${ }^{14,15,22,23}$.

Para ser efetivo, o preparo deve sempre começar no nível de desenvolvimento em que a criança se encontra e não pelo ponto que para o adulto seria lógico. Deste modo é necessário:

- avaliar as características individuais da criança. É necessário definir qual a habilidade individual da criança para assimilar informações, bem como sua forma de reagir quando enfrenta situações de estresse: fica inibida/ retraída ou faz perguntas e solicita ajuda? explora o ambiente ou permanece imobilizada ou agarrada à sua mãe chorando? tenta manter-se calma ou se torna agressiva? etc. ${ }^{10,14,22 ;}$

- investigar em relação a experiências anteriores de hospitalização/cirurgia e se estas deixaram cicatrizes emocionais ou representaram experiências de crescimento para a criança, sendo que este aspecto é válido tanto para experiências da própria criança como de pessoas próximas em sua vida ${ }^{14,22}$.

- explorar a respeito de crises simultâneas na vida da criança, tais como: entrada na creche ou escola, nascimento de um irmão, falecimento de um ser querido ou de um animal de estimação, mudança de vizinhança, etc. A crise da cirurgia representaria para a criança e sua família um estresse ainda maior $^{22}$;

indagar a respeito da possibilidade da mãe ou outro adulto significativo permanecer junto à criança no hospital, seja apenas como acompanhante ou como participante ativo nos seus cuidados; caso esta possibilidade exista, teremos o melhor aliado possível para prover a segurança e o apoio de que a criança precisa para enfrentar a cirurgia/hospitalização ${ }^{10,14,22}$;

- avaliar a percepção da criança e de seus pais em relação a situação atual, já que esta será de grande importância na deteç̧ão de quais as informações, tanto em relação à cirurgia como à própria hospitalização, que eles ainda desconhecem ou quais foram mal interpretadas. Conhecer e compreender a percepção da criança e de seus pais em relação à situação atual, ajudará a determinar a ajuda de que eles precisam ${ }^{10,14,15,22}$; e

- finalmente, é essencial informar-se em detalhes acerca do tipo de cirurgia proposto, tipo de anestesia que se pretende empregar, bem como a respeito das condições pós-operatórias esperadas (infusão endovenosa, drenos, sondas, gesso, etc.) para, assim, poder determinar quais as informações que precisamos veicular através do preparo. A quantidade das informações dependerá também do tempo disponível para realizar o preparo, isto é, de quando é iniciado o preparo para uma cirurgia eletiva ou se trata-se de uma cirurgia de emergência ${ }^{19,22}$. 


\section{RECURSOS NECESSÁRIOS PARA IMPLEMENTAR O PREPARO}

Os recursos ideias para realizar um preparo adequado podem ser divididos em duas categorias: materiais e humanos.

\section{- RECURSOS MATERLAIS:}

Embora não seja necessário equipamento especial para implementar o preparo, as crianças pequenas que ainda não têm a capacidade de pensar em termos de conceitos se beneficiam, e muito, com a utilização de objetos palpáveis que suplementam a explicação. Deve-se permitir que elas manuseiem e brinquem com os objetos reais que serão utilizados em sua assistência (máscara, gorro, pinça de curativo, etc.) Isto as ajuda a se familiarizarem com esses objetos e a diminuir a ameaça habitualmente a eles associada $6,10,14,15,22,24$.

Entre os recursos materiais que permitem adequar a explicação do procedimento ao nível de compreensão da criança, pode-se utilizar:

- Material para brinquedo de dramatização, 10, 13 junto com material próprio do brinquedo terapêutico ${ }^{1}, 4,10,11,13,14,17,18$.

O principal propósito do brinquedo terapêutico é o de propiciar à criança um meio seguro, não ameaçador, de expressar verbal e não verbalmente suas percepções, emoções e preocupações em relação à experiência de hospitalização4. Esta técnica, fundamentada nos princípios da ludoterapia, pode ser empregada por qualquer enfermeira com qualquer criança hospitalizada ${ }^{4}$ 13, 18, 22. Numa sessão de brinquedo terapêutico, cuja duração pode ser de 15 a 45 minutos, oferece-se à criança bonecos e instrumentos/utensílios que representam tanto o ambiente hospitalar quanto ofamiliar 1,4, 9, 10, 22. Durante a sessão, a enfermeira deve observar atentamente o comportamento da criança, mantendo sempre uma atitude nãodiretiva, isto é, não pode sugerir quais brinquedos a criança deveria utilizar, nem tentar conduzir a brincadeira. A enfermeira deve limitar-se a refletir ou repetir algumas expressões verbais da criança, o suficiente para encorajar a criança a continuar brincando e se expressando $0^{4}$ O observar atento do comportamento da criança durante a sessão aprofunda a compreensão da enfermeira das necessidades e sentimentos da criança $a^{1,4,11,13,18}$.

Já no brinquedo de dramatização, utilizam-se bonecos e objetos/ instrumentos de uso hospitalar para, na brincadeira com a criança, dramatizar os principais aspectos do procedimento a que ela será submetida. Durante uma sessão de brinquedo de dramatização, visualizando as situações e manuseando os instrumentos ou suas limitações, a criança receberá explicações concretas dos procedimentos ou descarregará a tensão após os mesmos ${ }^{9,10,13}$.

- folhelos e livros sobre estórias de crianças vivenciando situações similares à enfrentada pela criança $\mathrm{a}^{5,6,14,15,22 ;}$ 
- desenhos de traçados simples representando menino e menina para, desenhando neles, suplementar mais concretamente a explicação ${ }^{14,22}$;

- papel e lápis para, desenhando e utilizando a técnica menos ameaçadora da terceira pessoa, contar estória de uma criança o que ela faz nos hospital, o que irá acontecer com ela e com sua família, etc. Em geral, quando solicitada, a própria criança ajuda a completar a estória, revelando desse modo detalhes importantes para planejar a assistência ${ }^{12,22}$.

\section{- RECURSOS HUMANOS:}

Os recursos humanos necessários para preparar a criança e sua família para procedimentos hospitalares dizem respeito a:

- habilidades de comunicação verbal e não-verbal para estabelecer e manter relacionamento significativo e de confiança com a criança e sua família. Assim, a enfermeira que desempenha suas atividades profissionais em ambientes pediátricos, além de destreza na execução de procedimentos manuais de enfermagem pediátrica, deve ter grande habilidade em técnicas de comunicação efetiva e de relacionamento de ajuda, tanto com a criança como com sua família ${ }^{3}$. Conseqüentemente esta habilidade exige conhecimento dos processos de crescimento e desenvolvimento e também de dinâmica familiar.

- Com o objetivo de obter informações detalhadas sobre o tipo de cirurgia, tipo de anestesia que se pretende utilizar, condições pós-operatórias esperadas, bem como para dar continuidade e consistência ao preparo, é essencial a enfermeira ter habilidade para trabalhar em equipe multidisciplinar cirurgião, anestesista e com as enfermeiras de outras unidades, como centro cirúrgico (C.C.) e sala de recuperação pós-anestésica (RPA) entre outros ${ }^{3}$.

- e, por último, criatividade para, independentemente dos recursos materiais a seu dispor, improvisar meios que lhe auxiliem no preparo.

Convém lembrar que de pouco ou nada adiantam a riqueza dos recursos materiais e a posse das capacidades requeridas para implementar o preparo adequado da criança e sua família se a enfermeira não estiver sensibilizada para a necessidade de implantá-lo aliado à disposição e vontade de fazê-lo.

\section{QUANDO, ONDE E COMO IMPLEMENTAR O PREPARO}

\section{a) QUANDO}

O momento mais adequado para realizar o preparo varia de acordo com o tipo de cirurgia (eletiva ou de emergência) e com o nível de desenvolvimento da 
criança. Este momento varia também de acordo com as experiências passadas da criança e com o grau de ameaça a elas associado ${ }^{7,16}$.

No caso de cirurgia eletiva, o preparo deve ser feito de modo a dar tempo à criança para assimilar as informações e fazer perguntas, permitindo-lhe assim, mobilizar defesas adequadas, porém sem deixar tempo para o desenvolvimento de ansiedade excessiva ${ }^{14,16,22}$.

É necessário lembrar que, apesar da criança precisa de tempo para mobilizar suas defesas internas, ela necessita também ser ajudada a manter contato suficiente com a realidade para que não sucumba nas suas fantasias, $o$ que pode levá-la a intenso bloqueio, imobilizando-o de medo ou pânico' ${ }^{16}$.

No momento em que a decisão de operar é tomada, a situação deveria ser abertamente discutida com os pais. Folhetos e livros com estórias de crianças enfrentando situações similares são também de grande ajuda para os pais começarem a se preparar, de modo que quando se sentirem mais confiantes possam discutir o assunto com a criança; os folhetos e os livros antes mencionados podem ser de grande auxílio nessa discussão ${ }^{22}$.

Visitar o hospital antes da internação, quando esta visita puder ser agendada, e discutir os procedimentos com a enfermeira, pode ser muito benéfico, tanto para os pais como para a criança, particularmente aquelas no fim do período pré-escolar e no início da idade escolar, ou seja, entre 4 e $8 \operatorname{anos}^{2,14,15,22}$. No entanto, com crianças pequenas, em especial aquelas menores de 2 anos, a única medida preventiva realmente eficaz, como já há muito tempo apontado, é a internação antecipada, com a permanência da mãe como acompanhante. Esta através de oportunidades para expressar seus sentimentos, elaborar suas emoções e liberar ansiedade, para compreender os procedimentos, bem como a necessidade de executá-los. Mães confiantes e emocionalmente fortalecidas vão poder comunicar esta confiança a seus bebês e filhos pequenos ${ }^{16}$.

Quando o procedimento cirúrgico tem caráter de emergência, devem ser fornecidas à criança, de acordo com seu nível aproximado de desenvolvimento cognitivo, explicações honestas, curtas e simples, que transmitam confiança no procedimento e seus resultados ${ }^{19}$.

O preparo para procedimentos hospitalares inclui não apenas o antes, mas também o durante, como é o emprego de anestesia local no caso de cirurgia, e também o após ${ }^{9,10,22}$. Nas cirurgias de emergência este após deve ser amplamente aproveitado, de modo que a criança possa, através do método que for mais apropriado às suas características, elaborar suas emoções e adquirir, assim, uma compreensão adequada e real do que lhe aconteceu e porque.

É necessário enfatizar que no período de recuperação pós-operatória, tanto na cirurgia eletiva como na de emergência, além de continuar a elaborar as emoções e as idéias ou percepções em relação à cirurgia, a criança deve ser preparada para todos aqueles procedimentos que virão a seguir, como curativos, retirada de pontos, medicações, infusões endovenosas, coleta de amostras para novos exames, etc. ${ }^{14,22}$. 


\section{b) ONDE IMPLEMENTAR O PREPARO}

Idealmente o preparo da criança deveria ser realizado na sala de recreação, visto ser esta uma área neutra, livre de ameaças quando apropriadamente utilizada $^{2}$ 6, 14, 16, 22. Quando este espaço não existir, pode ser utilizado o local destinado às refeições ou o próprio leito da criança.

Quanto ao preparo dos pais, estes, além de se beneficiarem de acompanhar o preparo da criança, devem também ser preparados separadamente para, deste modo, terem a oportunidade de expressar seus sentimentos, verbalizar dúvidas, solicitar informações adicionais, uma vez que seu nível de compreensão é diferente do da criança. Para este preparo ser possível, faz-se necessário um ambiente adequado, se possível privativo e livre de quaisquer interferências ${ }^{22}$.

\section{c) COMO FAZER O PREPARO DA CRIANCA}

Uma vez que o preparo adequado varia de acordo com o nível de desenvolvimento da criança, com suas características individuais, experiências anteriores e/ou simultâneas de estresse e tipo de cirurgia, entre outros, apontaremos a seguir alguns principios gerais que servem de orientação aó como implementar o preparo para procedimentos hospitalares ${ }^{2,6,7,8,9,10,14,15}$, $16,22,24$

- A abordagem e o método de escolha, inclusive se individual ou em grupo, devem respeitar o nível de desenvolvimento da criança, bem como a forma habitual em que ela reage ao estresse.

- O preparo deve ser feito por alguém em quem a criança confie e de maneira gradual, já que, devido às características de seu desenvolvimento cognitivo-emocional, a capacidade da criança para assimilar conceitos ameaçadores é muito limitada.

- $\quad$ As explicações devem ser curtas, honestas e diretas, em linguagem simples e objetiva, em termos do que acontecerá, do que a criança pode vir a sentir e como ela pode colaborar. Se contarmos à criança o que ela deve esperar e como pode ajudar, estaremos capitalizando forças, pois a criança ficará confiante se tudo o que for dito se confirmar na realidade.

- Explicar todos os procedimentos que serão realizados antes e após a cirurgia e permitir que a criança pratique todos os procedimentos que vão precisar de sua cooperação, como tossir, virar-se, respirar profundamente, etc.

- Utilizar termos concretos junto com o auxílio de recursos visuais para descrever o procedimento, como, por exemplo, um desenho de traçado simples ou, quando possível e apropriado, utilizar brinquedo de dramatização, demonstrando o procedimento nos bonecos.

- Repetir várias vezes a explicação, permitindo à criança oportunidades para perguntar e falar várias vezes sobre o assunto. 
- Desde que a criança seja capaz, deixá-la manusear e brincar com o equipamento de dramatização.

- Nas repetições do preparo deve-se observar quais fatos da situação foram assimilados, quais os que estão sendo mal interpretados e quais estão sendo negados, para assim poder determinar a ajuda de que a criança precisa.

- Quando a criança usa negação como mecanismo de defesa, é necessário romper essa barreira sempre com a verdade, ainda que aparentemente nossas palavras não sejam ouvidas.

- Lembrar que, conforme seu desenvolvimento, a criança não tem capacidade para compreender tudo o que ouve durante o preparo, mas, com certeza, receberá a mensagem de que queremos ajudá-la.

- Sempre que possível visitar a RPA com a criança e seus pais como também a UTI, quando uma estadia da criança nessa unidade for esperada, sem esquecer de apresentar as enfermeiras responsáveis por essas unidades.

- Encorajar os pais, particularmente aqueles de crianças menores de 5 anos, a permanecerem junto ao filho tanto quanto for possível ou permitido pela instituição.

- Comunicação à criança onde se encontrarão seus pais enquanto ela está no C.C.

- Permitir que algum objeto significativo para a criança, seu brinquedo favorito por exemplo, a acompanhe.

- Providenciar para que, dentro do possível, a criança se recupere totalmente dos efeitos da anestesia do lado de seus pais.

- Elogiar a criança: ela necessita ouvir das outras pessoas que elas sabem que ela fez o melhor que podia na situação - independentemente de qual tenha sido seu comportamento. É importante que ela saiba que seu valor não está sendo julgado com base em seu comportamento em uma situação estressante. Pode-se elogiar por ter feito o melhor que podia com pequenas recompensas, como certificados por mérito, adesivos, etc.

- Voltar ao lado da criança logo após o procedimento ajuda a enfermeira a reforçar um relacionamento positivo com a mesma. Relacionar-se com a enfermeira durante um período de relaxamento e não-estresse permitel que a criança a perceba não apenas como alguém associada a situações estressantes, mas como alguém com quem também pode partilhar experiências agradáveis.

De modo geral, recomenda-se os seguintes métodos ${ }^{26,14,15,16,22 .}$

- crianças até 1,5 - 2 anos: preparar suas mães;

- crianças de 2 a 4 anos: dramatizar os aspectos mais relevantes do procedimento, tais como: pessoas usando avental, máscara e gorro; a anestesia 
é um "cheirinho" ou "um remédio para você dormir e não sentir dor"; acordar junto aos pais, etc.

- crianças de 4 a 6 anos: utilizar amplamente o "brinquedo de dramatização" e o "brinquedo terapêutico";

- $\quad$ escolares no início do período: "brinquedo de dramatização";

- escolares maiores: explanação com auxílio de desenhos sobre o quê acontecerá e porquê; permitir escolhas possíveis como o local de aplicação do pré-anestésico; permitir privacidade para o banho e para se vestir para o C.C.;

- adolescentes: fornecer o máximo de informação de acordo com suas necessidades, considerando suas preocupações com sua imagem corporal e sua integridade; permitir escolhas possíveis e privacidade para o banho e para se vestir para o C.C.; a permanência dos pais dependerá da escolha do adolescente.

Fazendo uma síntese, os princípios que regem o preparo da criança para a cirurgia incluem:

- determinar os detalhes exatos da cirurgia proposta, incluindo tipo de anestesia que será utilizado e as condições pós-operatórias esperadas;

- avaliar o nível de compreensão tanto da criança como de seus pais;

- planejar o preparo com base no nível de compreensão da criança e de acordo com sua percepção em relação ao que acontecerá;

- envolver os pais no preparo; e

- durante o preparo permitir oportunidades para discutir amplamente a respeito do procedimento e de seu propósito, do que a criança pode vir a sentir e apresentar antes e após a cirurgia; sem esquecer o durante no caso do emprego de anestesia local.

Durante o periodo de recuperação deve-se dedicar à criança algum tempo com o objetivo de explorar sua percepção da cirurgia. Brincar, desenhar e contar estórias são excelentes métodos para descobrir os pensamentos das crianças. O brinquedo de dramatização e o brinquedo terapêutico servem para a criança, particularmente a criança pequena, exteriorizar seus conflitos 5 , 9. Com tais informações a enfermeira pode reforçar ou corrigir as percepções da criança e auxiliá-la a dominar a experiência de se submeter a um procedimento estressante $^{22}$. 


\section{O QUE ESPERAR DA CRIANÇA QUE FOI PREPARADA}

É freqüente os pais e também a equipe hospitalar imaginarem que o preparo adequado fará a criança enfrentar a cirurgia como um "cordeiro" que até se mostra contente de ir para a mesa de operação. A experiência de alguns pesquisadores nos mostra que casos como esse, "cordeiro", são apenas exemplos de submissão, que correspondem a reações que refletem a falta de preparo e que, portanto, a criança ignora o que a espera, ou que correspondem então a reações de intenso bloqueio emocional" ${ }^{16}$.

Embora o preparo ofereça condições para a criança expressar suas emoções, esta não muda imediatamente seu comportamento. Assim sendo, nunca se deve esperar que a criança não reaja e não chore., havendo às vezes necessidade de ajudar uma criança que fora adequadamente preparada, restringindo- ${ }^{222}{ }^{23}$.

Um dos objetivos do preparo é ajudar a criança a enfrentar da maneira mais sadia possível aquilo que não pode ser evitado e o resultado, eminentemente individual, é uma reação de medo adequada à realidade da experiência, isto é, uma reação diferente do pânico por um lado e da negação por outro, pois ambos implicam em perda de contato com a realidade ${ }^{2}$.

Devemos esperar também que a criança mantenha ou fortaleça sua capacidade de interagir e de brincar, aproveitando ao máximo as oportunidades de repetir a experiência no brinquedo, passando de sujeito passivo (vítima) a instigador e controlador ativo ${ }^{13}$. O brincar é a forma infantil da capacidade humana para lidar com as experiências e dominar a realidade ${ }^{13}$.

Somente quando o preparo da criança para procedimentos cirúrgicos incluir, não apenas o preparo físico adequado, mas também os aspectos psicoemocionais da criança e de sua família considerados neste trabalho, é que estaremos atendendo ao objetivo central que deve orientar a nossa assistência à criança hospitalizada: "proteger e favorecer seu desenvolvimento integral e não apenas restaurar e manter sua saúde física"21.

NEIRA HUERTA, E. del P. Preparing the child and his family for surgical procedures: nursing intervention. Rev.Esc.Enf.USP, v.30, n.2, p.340-53, aug. 1996.

In this paper the author presents the essentials of the psychologically preparation of the child and his family for surgical procedures, discussing as well other relevant factors, such as: what to consider to make an appropriate preparation; necessary resources to implement it; when, where and how to do it, and also what to expect from the appropriately prepared child.

UNITERMS: Preparing the child for surgery and hospital procedures. Pediatric nursing. 


\section{REFERÊNCIAS BIBLIOGRÁFICAS}

1. ANGELO, M. Brinquedo: um caminho para a compreensão da criança hospitalizada. Rev.Esc.Enf.USP, v. 19, n.3, p. 213-23, 1985.

2. BATES, T.A.; BROOME, M. Preparation of children for hospitalization and surgery: a review of the literature. J.Pedriatr.Nurs., v.1, n.4, p. 230-9, 1986.

3. EYRES, P. The role of the nurse in the family-centered care. Nurs. Clin. North Amer., v. 7. n. 1, p. 27-39, 1972 .

4. GREEN, C.S. Understanding children's needs through therapeutic play. Nursing, v.4, n. 10 p. 31-2, 1974 .

5. HOWE, J.; SCIPIEN, G.M. The hospitalization of a child. In: SCIPIEN, G.M. et al. Pediatric nursing care. St. Louis, Mosby, 1990. cap.9.

6. JOLLY, J. The other side of paediatrics: a guide to the everyday care of sick children. London, The Macmillan Press, 1982.

7. LUCIANO, K.; SHUMSKY, C.J. Pediatric procedures: the explanation should always come first. Nursing, v.5, n.1, p. 49-52, 1975.

8. MARTINS, D.M.R. Assistência de enfermagem às crianças hospitalizadas quando enfrentam situaçōes desagradáveis: parte I. Rev.Esc.Enf.USP, v. 13, n.2, p. 157-59, 1979.

9 Assistência de enfermagem às crianças hospitalizadas quando enfrentam situaçōes desagradáveis: parte II. Rev.Esc.Enf.USP, v.13, n.3, p. 287-99, 1979.

10. MORAES, E. Guias de estudo de enfermagem pediátrica. Rev.Esc.Enf.USP, v.6, n.1/2, p. $7-128,1972$.

11. _________tudantes de enfermagem assistem crianças utilizando "entrevista com brincadeira". Rev.Esc.Enf.USP, v. 13, n.1, p. 29-39, 1979.

12. __ Mensagem única: um modo terapêutico de tratar crianças em sofrimento. Rev.Esc.Enf.USP, v. 14, n.2, p. 165-9, 1980.

13. NEIRA HUERTA, E. del P. Brinquedo no hospital. Rev.Esc.Enf.USP, v. 24, n. 3, p. 319 . 28,1990 .

14. PETRILLO, M.; SANGER, S. Cuidado emocional del nino hospitalizado. México, Prensa Médica, 1975.

15. PLANK, E. El cuidado psicológico del nino enfermo en el hospital. Buenos Aires, Paidós, 1966.

16. PSICOPROFIlAXIA CIRÚRgICA São Paulo. Grupo de Estudo da Pediatria Social do Instituto da Criança do HC - FMUSP, 1980/mimeografado/. 
17. RIBEIRO, C.A. Sentindo o valor das experiências significativas para a aprendizagem: relato de duas situações vividas com crianças hospitalizadas. Rev.Esc.Enf.USP, v.17, n.3, p. 179-203, 1983.

18 O efeito da utilização do brinquedo terapêutico, pela enfermeira pediatra, sobre o comportamento de crianças recém-hospitalizadas. Rev.Esc.Enf.USP, v.25, n.1, p. 41-60, 1991.

19. ROSKIES, E. el al. Emergency hospitalization of young children: some neglected psychological considerations. Med.Care, v.13, n.7, p. 570-81, 1975.

20. SOPARKAR, B.A.P. Trichery, white lies and deception in pediatrics. Nursing, v.4, n.1, p. 11-13, 1974.

21. WHALEY, L.F.; WONG, D.L. Nursing care of infants and children. 4th ed. St. Louis, Mosby, 1991, cap. 26: Reaction of the child and family to illness and hospitalization.

22. Nursing care of infants and children. 4th ed. St. Louis, Mosby, 1991, cap. 26: Pediatric variations of nursing interventions.

23. WONG, D.L.; WHALEY, L.F. Clínical manual of pediatric nursing. 3rd ed. St. Louis, Mosby, 1990.

24. WU, R. Explaining treatments to young children. Am. J.Nurs., v.65, n.7, p. 71-3, 1965 